\title{
Evaluation of antitumor activity of Artemisia capillaris extract against hepatocellular carcinoma through the inhibition of IL-6/STAT3 signaling axis
}

\author{
EUNGYEONG JANG ${ }^{1 *}$, SO-YOUNG KIM ${ }^{2 *}$, NA-RAE LEE ${ }^{2}$, CHAE-MIN YI $^{2}$, \\ DA-RONG HONG ${ }^{2}$, WOO SEOK LEE ${ }^{3,4}$, JONG-HO KIM ${ }^{2}$, KYUNG-TAE LEE ${ }^{3,4}$, \\ BUM-JOON KIM ${ }^{5}$, JANG-HOON LEE ${ }^{1}$ and KYUNG-SOO INN ${ }^{2,6}$
}

\begin{abstract}
${ }^{1}$ Department of Internal Medicine, College of Korean Medicine, Kyung Hee University; ${ }^{2}$ Department of Pharmaceutical Science, College of Pharmacy, Kyung Hee University; Departments of ${ }^{3}$ Pharmaceutical Biochemistry and ${ }^{4}$ Life and Nanopharmaceutical Science, College of Pharmacy, Kyung Hee University, Seoul 02447; ${ }^{5}$ Department of Biomedical Sciences, Microbiology and Immunology, and Liver Institute, College of Medicine, Seoul National University, Seoul 03080;

${ }^{6}$ East-West Medical Research Institute, Kyung Hee University, Seoul 02447, Republic of Korea
\end{abstract}

Received June 20, 2016; Accepted November 14, 2016

DOI: $10.3892 /$ or.2016.5283

\begin{abstract}
Interleukin-6 (IL-6)/signal transducer and activator of transcription 3 (STAT3) signaling pathway plays critical roles in the development and progression of hepatocellular carcinoma (HCC). Artemisia capillaris (AC) has been widely used to treat various liver diseases including $\mathrm{HCC}$ as a herbal medicine. The effects of AC on IL-6/STAT3 signaling axis in $\mathrm{HCC}$ cells and subsequent anticancer activity of AC against HCC were analyzed using HCC cell lines and HBV W4P-LHBexpressing NIH3T3 cell line, which has been shown to gain tumorigenicity by activating IL-6/STAT3 signaling in our previous study. AC extract significantly suppressed the growth and colony formation of HCC cells. In addition, it inhibited the activation of STAT3 by IL- 6 and subsequent synthesis of downstream molecules in HCC and W4P-NIH3T3 cells. Consequently, migration of cells was significantly suppressed by the AC extract. Collectively, the findings suggest that $\mathrm{AC}$
\end{abstract}

Correspondence to: Dr Jang-Hoon Lee, Department of Internal Medicine, College of Korean Medicine, Kyung Hee University, 26 Kyungheedae-ro, Dongdaemun-gu, Seoul 130-701, Republic of Korea

E-mail: komclive@khmc.or.kr

Dr Kyung-Soo Inn, Department of Pharmaceutical Science, Room 404, College of Pharmacy, Kyung Hee University, 26 Kyungheedae-ro, Dongdaemun-gu, Seoul 130-701, Republic of Korea

E-mail:innks@khu.ac.kr

${ }^{*}$ Contributed equally

Key words: Artemisia capillaris, hepatocellular carcinoma, STAT3, interleukin-6, antitumor activity, migration extract is capable of conferring various antitumor effects against HCC through the modulation of the IL-6/STAT3 pathway. The results provide a basis for the therapeutic use of $\mathrm{AC}$ in the treatment of HCC. Identification of the compound responsible for the effect may lead to the development of a novel anticancer agent against HCC.

\section{Introduction}

The pathogenesis of hepatocellular carcinoma (HCC) is closely linked with chronic inflammation and the level of interleukin-6 (IL-6). Serum IL-6 level is higher in HCC patients than in healthy adults (1), demonstrating that inflammation is a critical risk factor for the formation and progression of HCC. IL-6 rapidly activates the signal transducer and activator of transcription 3 (STAT3), which is a major mediator regulating signal transduction from IL-6 to the nucleus and inducing the transcription of proliferation associated genes (2). Phosphorylated STAT3 has been implicated in abnormal oncogenic processes, such as initiation, proliferation, angiogenesis, and progression in HCC (3). Owing to these carcinogenetic roles of the IL-6/ STAT3 signaling pathway, which promotes the development of HCC, STAT3 is often considered an attractive target for liver cancer therapy. In addition, in our previous study, we found that male-specific W4P mutations in the preS1 region contribute to carcinogenesis and male predominance in $\mathrm{HCC}$ via activation of the IL-6/STAT3 signaling axis. Ectopic expression of W4P mutant HBV large antigen (LHB) was sufficient to induce transformation of NIH3T3 fibroblast cells, emphasizing the crucial role of the IL-6/STAT3 signaling pathway in HCC carcinogenesis (4).

Artemisia is one of the most important genera of the Asteraceae or Compositae family, the largest family of flowering plants with over 15,000 species (5). The genus Artemisia consists of more than 400 species, some of which exhibit medicinal activities for a variety of diseases such as malaria, rabies, tonsillitis, asthma, gonorrhea, cough, syphilis, 
and leprosy (6). Amongst these species, Artemisia capillaris Thunberg (AC) has long been used in Asian countries as a therapeutic drug $(7,8)$. According to previous studies on its medicinal properties, AC exhibits various pharmacological effects, such as antimicrobial (8), anti-obesitic $(9,10)$, and antitumor (11) effects. In particular, there have been many studies on the therapeutic and pharmacological effects of AC against liver diseases, including hepatoprotective effects in obese mice (12) or ethanol-administered mice (13), antiviral effects by suppressing the replication and secretion of the hepatitis $B$ virus (14-16), and anti-fibrotic effects in animal models $(7,17,18)$.

$\mathrm{HCC}$, the most common primary liver cancer, demands more effective remedies because of a low 5-year survival rate, about $10 \%$ (19), and poor reactions refractory to available treatments (20). Increasing evidence indicates the efficacy of AC in suppressing the proliferation of human hepatoma cells (21-23). In a recent study, capillarisin derived from $\mathrm{AC}$ was found to have anticancer effects by suppressing STAT3 phosphorylation in human multiple myeloma cells (24). However, there have been no previous studies evaluating the anticancer effects of AC via inhibition of the STAT3 signaling pathway in vitro models of HCC.

Therefore, in this study, we examined the possibility of AC exerting its antitumor activity against $\mathrm{HCC}$ by modulating IL-6-induced STAT3 activation.

\section{Materials and methods}

Preparation of AC extract (ACE). AC was purchased from Kyung Hee Herb Pharm (Wonju, Korea), a licensed herb company. AC was pulverized and extracted with $70 \% \mathrm{EtOH}$ under reflux three times, and the extract was filtered and evaporated on a rotary evaporator under reduced pressure and then lyophilized. ACE was subjected to LC-MS/MS analysis and Scopoletin and liquiritin were found to be present at concentrations of $393.3 \pm 45.7 \mu \mathrm{g} / \mathrm{g}$ and $39.33 \pm 6.3 \mu \mathrm{g} / \mathrm{g}$, respectively.

Cells. Huh7 and HepG2 human hepatocellular carcinoma cells were maintained in Dulbecco's modified Eagle's medium (DMEM) containing 10\% fetal bovine serum (FBS) and penicillin/streptomycin $(100 \mathrm{U} / \mathrm{ml})$. NIH3T3-W4P cell line expressing W4P mutant LHB was established and maintained as previously described (4).

Cell viability assay. Anti-proliferative effects of ACE on HCC cells were analyzed using the 3-(4,5-dimethylthiazol2-yl)-2,5-diphenyltetrazolium bromide (MTT) assay. Huh7 and HepG2 cells were treated with increasing concentrations of ACE for $72 \mathrm{~h}$ followed by further incubation with the MTT-containing medium for $4 \mathrm{~h}$. After lysis with dimethyl sulfoxide, the absorbance of lysates was determined at $570 \mathrm{~nm}$ by using a microplate reader.

Colony forming assay. Six-hundred Huh7 cells and 200 cells of NIH3T3-W4P were seeded onto 6-well plates and incubated for $24 \mathrm{~h}$. The NIH3T3 and Huh7 cells were then treated with different concentrations of ACE for 3 and 8 days, respectively. Colonies were fixed with $100 \%$ methanol for $10 \mathrm{~min}$ and then stained with $0.1 \%$ crystal violet for an hour. After washing with PBS, the number of colonies was counted.
Immunoblotting. The effect of ACE on the phosphorylation status of STAT3 was analyzed by immunoblotting. HepG2 cells were treated with ACE for $3 \mathrm{~h}$ prior to treatment with IL-6 $(25 \mathrm{ng} / \mathrm{ml})$. After incubation for $25 \mathrm{~min}$, the cells were lysed and the cell lysates were subjected to immunoblotting using anti-STAT3 (Santa Cruz Biotechnology, sc-482), anti-phosphoSTAT3 (Cell Signaling, \#9131), and anti- $\beta$ actin antibodies (Santa Cruz Biotechnology, sc-47778). To analyze the effect of ACE on the expression of cyclin D2 and P21, HepG2 cells were treated with ACE for $48 \mathrm{~h}$ and subjected to immunoblotting using anti-cyclin D2 (Santa Cruz Biotechnology, sc-593) and anti-P21 (Santa Cruz Biotechnology, I2807) antibodies.

$R N A$ preparation and reverse-transcription quantitative $P C R(R T-q P C R)$. To determine the effect of ACE on the mRNA levels of cyclin D1, which are dependent on STAT3 transcriptional activity, RT-qPCR assays were performed. HepG2 cells and NIH3T3-W4P cells were treated with the increasing concentrations of ACE for 4 and $8 \mathrm{~h}$, respectively. Total RNA was extracted using an RNeasy RNA extraction kit (Qiagen) according to the manufacturer's instructions. cDNA was synthesized from RNA using Superscript III reverse transcriptase (Invitrogen) with oligo20(dT) primers and analyzed by real-time PCR.

Scratch wound assay. Effect of ACE on Huh7 cell migration was investigated by performing a scratch wound assay. The confluent monolayer of Huh7 cells in a 6-well plate was wounded with a sterile pipette tip and incubated with increasing concentrations of ACE for $48 \mathrm{~h}$. The cells were observed and images were obtained at 24 and $48 \mathrm{~h}$ after the treatment.

Transwell cell migration assay. Cell migration assay was performed as previously described (25). Briefly, after being treated with $\operatorname{ACE}(0,25,50,100$, and $200 \mu \mathrm{g} / \mathrm{ml})$ for $24 \mathrm{~h}$, Huh7 cells were harvested and seeded on a Boyden chamber (Neuro Probe, Cabin John, MD, USA) at a density of $10^{5}$ cells per well in a serum-free medium and then incubated for $6 \mathrm{~h}$ at $37^{\circ} \mathrm{C}$. The migrated cells were fixed with $100 \%$ methanol and stained with $5 \%$ Giemsa. Cells were counted under a light microscope.

Statistics. Statistical analysis was performed by SigmaPlot 10.0. Data are shown as means $\pm \mathrm{SD}$, and group differences were analyzed using paired Student's t-test. $\mathrm{p}<0.05$ was considered as statistically significant.

\section{Results}

Anticancer effects of ACE on HCC cell lines. AC has been well known for its therapeutic effect in liver diseases and several previous studies suggested its antitumor activity. Here, we evaluated the anticancer activity of ACE on HCC by examining its effect on HCC cell proliferation by MTT assay. ACE displayed significant anti-proliferative effects against Huh7 and HepG2 human hepatoma cell lines in a dose-dependent manner (Fig. 1A and B). To further confirm the anticancer effect of ACE, its effect on the colony-forming ability of HCC cells was examined. As shown in Fig. 2, the colony formation 

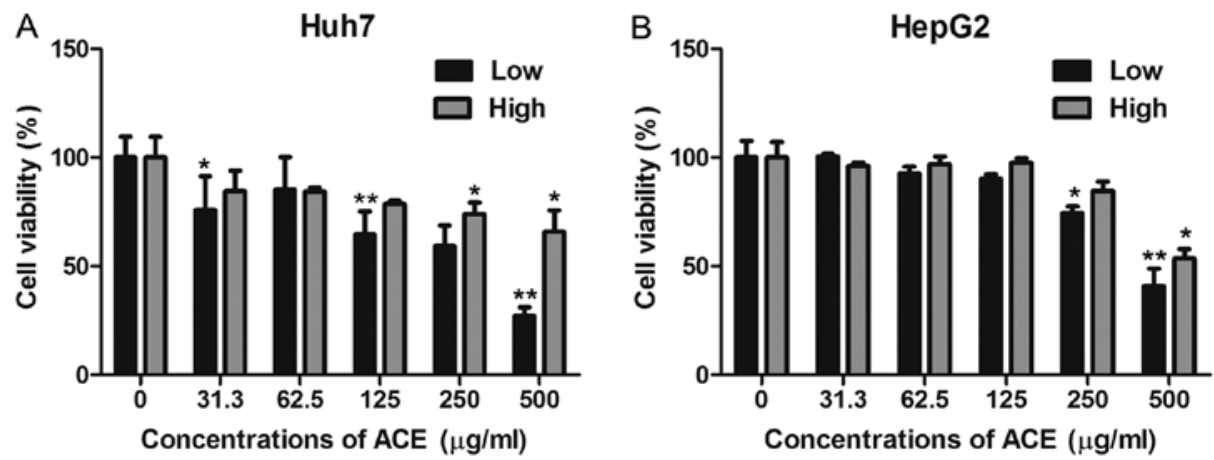

Figure 1. Anticancer activity of ACE in HCC cell lines. Antiproliferative effect of Artemisia capillaris extract (ACE) on Huh7 (A) and HepG2 cells (B) was examined by MTT assay. Different number of cells $\left[5 \times 10^{3}\right.$ cells/well (Low); $5 \times 10^{4}$ cells/well (High)] were incubated with the indicated concentrations of ACE for $72 \mathrm{~h}$ and subjected to MTT assays to determine the cell viability. Data represent means $\pm \mathrm{SD}$. ${ }^{*} \mathrm{p}<0.05,{ }^{* *} \mathrm{p}<0.01$.
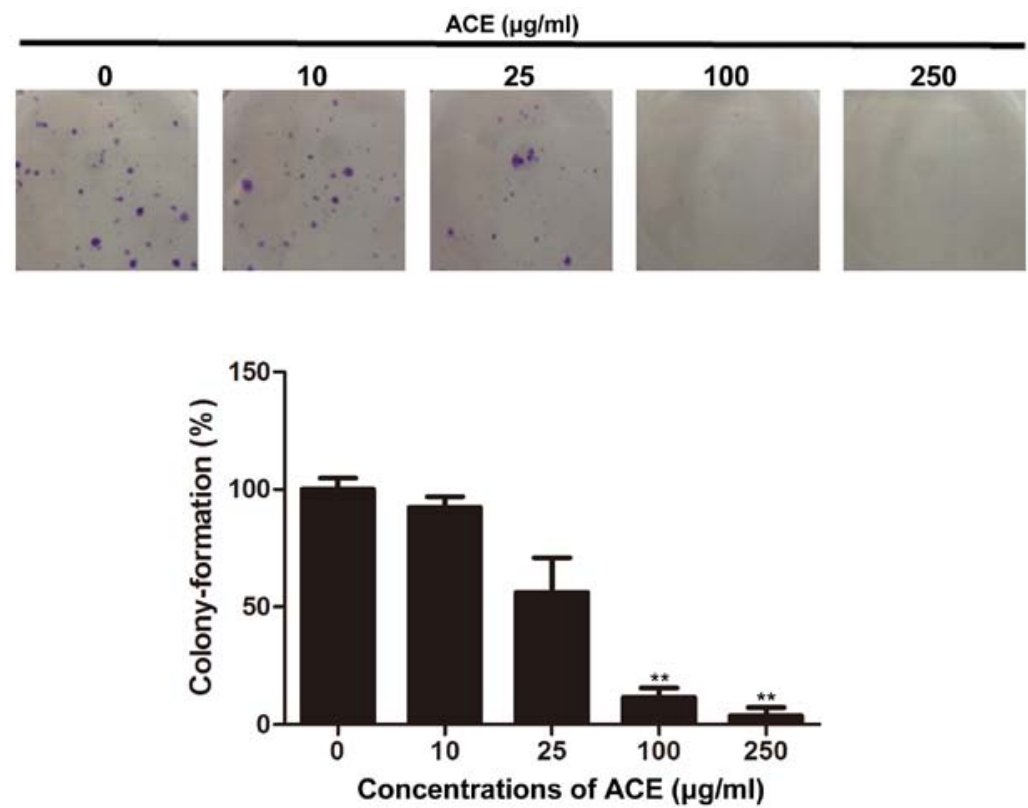

Figure 2. Effect of ACE on colony-formation by HCC cells. Colony-forming abilities of Huh7 cells were examined by a colony-forming assay in the absence or presence of increasing concentrations of ACE. Upper panel shows the crystal violet-stained colonies. Data represent means \pm SD. ${ }^{* *} \mathrm{p}<0.01$.

of Huh7 cells was significantly inhibited in the presence of ACE; $100 \mu \mathrm{g} / \mathrm{ml}$ of ACE treatment resulted in $90 \%$ reduction of the colony formation. Compared to its direct cell cytotoxicity and the suppression of cell proliferation, ACE exerted potent inhibitory effect on colony forming.

Inhibition of STAT3 activation in HCC cell lines by ACE. Inhibition of proliferation and colony formation of HCC cells by ACE indicate its anticancer effect against HCC. Given that IL-6-mediated STAT3 activation is implicated in HCC development and progression, the role of ACE in STAT3 activation was examined. IL- 6 treatment induced strong phosphorylation of STAT3, which is a hallmark of STAT3 activation in HepG2 cells. Treatment of IL-6-treated HepG2 cells with ACE resulted in marked decrease of both STAT3 and phosphorylated STAT3, indicating that ACE is capable of suppressing the action of STAT3 (Fig. 3A). Since STAT3 upregulates the transcription of cell cycle related genes including cyclin D1 and p21 and enhances cell cycle progression, the effect of ACE on the amounts of cyclin D1 and p21 was examined.
Consistent with the suppression of STAT3 phosphorylation by ACE, synthesis of cyclin D1 mRNA as well as protein levels of cyclin D2 and p21 were also decreased by ACE treatment (Fig. 3B and C).

Inhibition of $H B V$ W4P mutant large surface proteininduced STAT3 activation by ACE. In our previous study, we showed that male-specific W4P mutant HBV LHB drives HCC tumorigenesis by activating the IL-6/STAT3 signaling pathway (4). Thus, we evaluated whether ACE suppresses the STAT3 activation induced by W4P LHB. NIH3T3 cells stably expressing W4P LHB (NIH3T3-W4P) showed strong STAT3 phosphorylation compared to control NIH3T3 cells and the phosphorylation was decreased by ACE (Fig. 4A). The activity of ACE was dose-dependent and $100 \mu \mathrm{g} / \mathrm{ml}$ of ACE was sufficient to lower the phosphorylation to significant extent (Fig. 4B). In line with the results, cyclin D1 mRNA level of NIH3T3-W4P was also decreased in a dose-dependent manner by ACE treatment, further confirming that ACE suppresses the transcriptional activity of STAT3 (Fig. 4C). It has been 

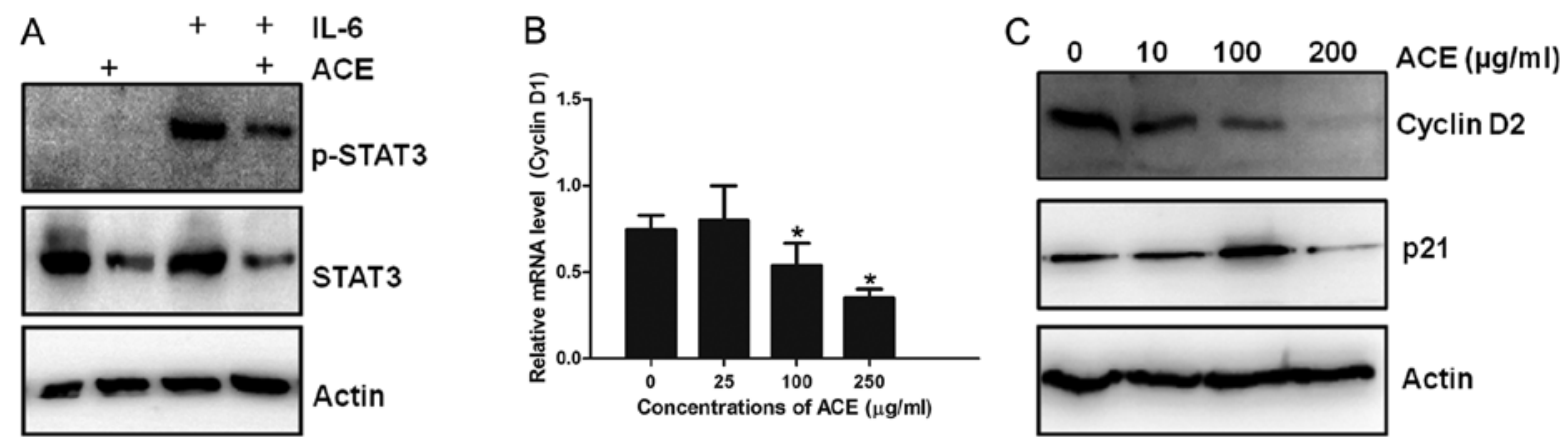

Figure 3. Inhibition of STAT3 transcriptional activity by ACE. (A) HepG2 cells were treated with ACE (100 $\mu \mathrm{g} / \mathrm{ml}) 3 \mathrm{~h}$ prior to IL-6 treatment ( $25 \mathrm{ng} / \mathrm{ml})$ for $25 \mathrm{~min}$ as indicated. Cells were lysed and the lysates were subjected to immunoblotting using antibodies against STAT3, pSTAT3 (pT705), and $\beta$-actin. (B) HepG2 cells were treated with ACE for $3 \mathrm{~h}$, followed by treatment with IL-6 for 4 or $8 \mathrm{~h}$. Relative amount of cyclin D1 mRNA levels in the samples were determined by RT-qPCR. Data represent means \pm SD. "p<0.05. (C) HepG2 cells were treated with the indicated concentrations of ACE for $48 \mathrm{~h}$. The protein levels of cyclin D2 and p21 were analyzed by immunoblotting.
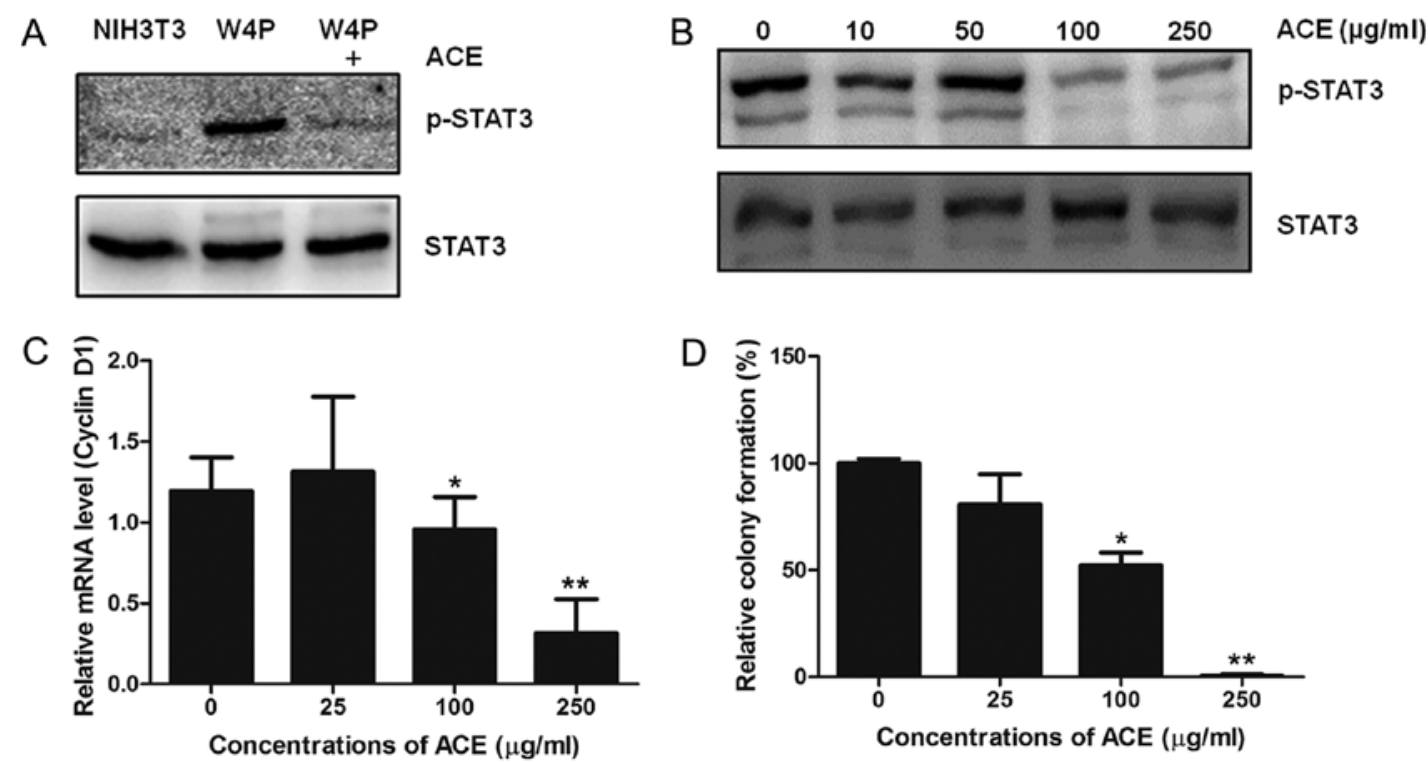

Figure 4. Effect of ACE on STAT3 activation induced by W4P mutant LHB. (A) NIH3T3 cells expressing HBV W4P large surface protein (W4P) (NIH3T3-W4P) were incubated with or without ACE $(100 \mu \mathrm{g} / \mathrm{ml})$ for $9 \mathrm{~h}$. Phosphorylation of STAT3 (pT705) was analyzed by immunoblotting using anti-phosphoSTAT3. (B) NIH3T3-W4P cells were incubated with increasing concentrations of ACE for $9 \mathrm{~h}$ and analyzed by immunoblotting as in (A). (C) NIH3T3-W4P cells were treated with the indicated concentrations of ACE for $8 \mathrm{~h}$. mRNA levels of cyclin D1 were analyzed by RT-qPCR using cDNAs synthesized from extracted total RNAs. (D) Effect of ACE on the colony-forming ability of NIH3T3-W4P was examined by colony-formation assay. Data represent means \pm SD. ${ }^{*} \mathrm{p}<0.05,{ }^{* *} \mathrm{p}<0.01$.

shown that W4P LHB confers in vitro colony forming ability and in vivo tumor forming capability in nude mice to NIH3T3 cells by activating the STAT3 signaling pathway (4). Since ACE suppresses STAT3 activation in NIH3T3-W4P cells, we evaluated whether ACE suppresses the colony-forming capability of NIH3T3-W4P cells. As shown in Fig. 4D, ACE treatment decreased the number of colonies in a dose-dependent manner, and $250 \mu \mathrm{g} / \mathrm{ml}$ of ACE almost completely abolished the colonyforming ability of NIH3T3-W4P cells. These results suggest that ACE is capable of suppressing tumorigenesis induced by HBV mutations and subsequent inflammatory responses including STAT3 activation in addition to HCC cell proliferation.

Suppressive effects of ACE on HCC cell migration. STAT3 has been implicated in cancer cell migration and invasion through the upregulation of pro-migratory genes including MMP-2 (26). In the absence of ACE, Huh7 cells migrated along the edge and repaired approximately $30 \%$ of the wound after $48 \mathrm{~h}$. Significant suppression of cell migration and wound recovery were observed in the presence of ACE and the inhibitory activity was concentration-dependent (Fig. 5A and B). Cell migration assay using Boyden chamber showed similar result. Treatment with $200 \mu \mathrm{g} / \mathrm{ml}$ of ACE suppressed over $95 \%$ of cell migration further confirming the suppressive activity of ACE on tumor cell migration (Fig. 6).

\section{Discussion}

AC has been widely used as a traditional remedy for various liver diseases in Asian countries. In the present study, we showed that ACE moderately suppressed the proliferation of HCC cells and it exerted stronger effect on colony-forming activity of HCC. In addition, we have shown that ACE treatment effectively suppressed STAT3 activation resulting in 

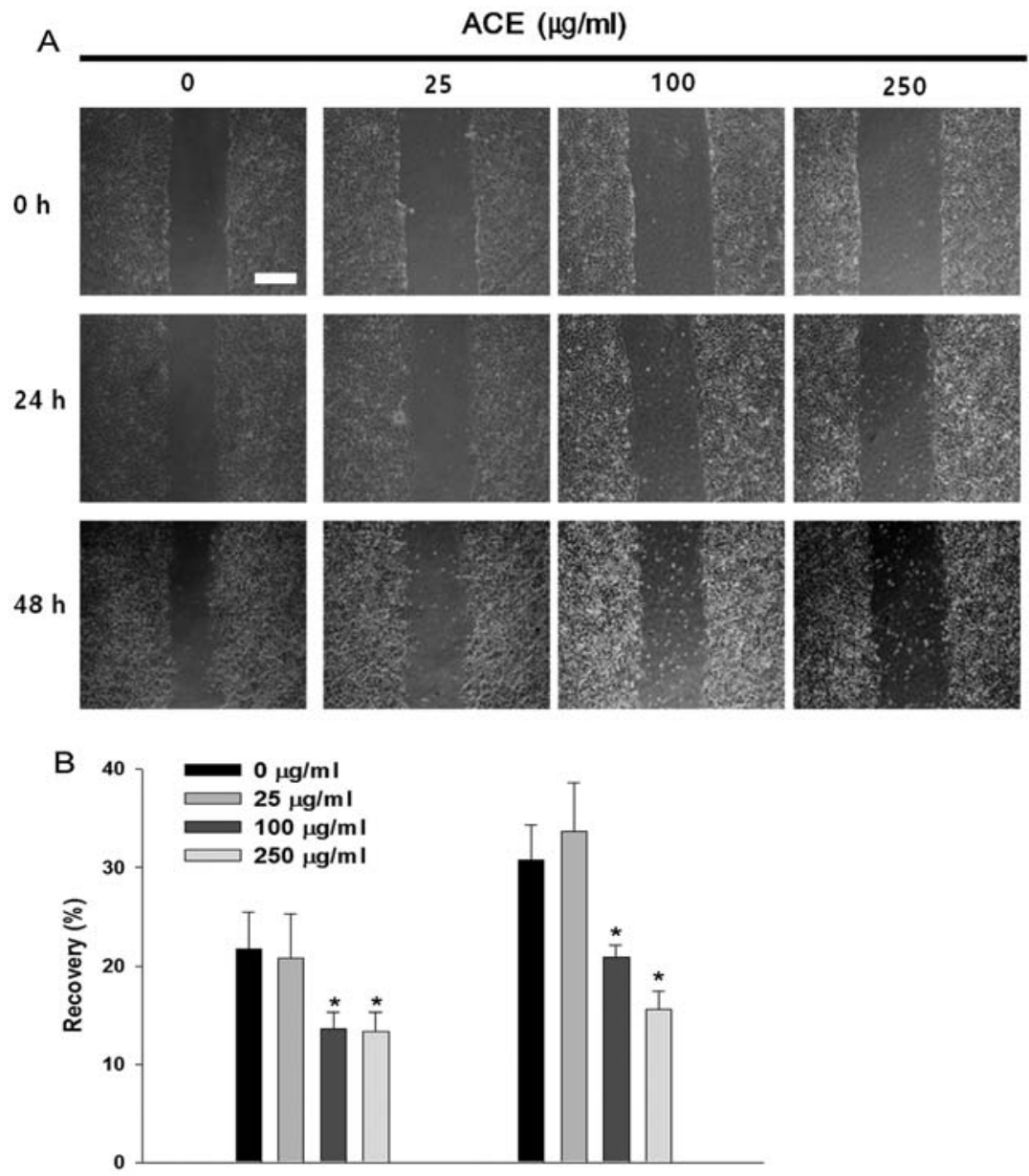

Figure 5. Effect of ACE on migration of Huh7 cells. (A) Effect of ACE on HCC cell migration was assessed by a scratch wound assay as described in Materials and methods. The area of the wound was measured at 24 and $48 \mathrm{~h}$ after treatment. Scale bar $=5 \mu \mathrm{m}$. (B) The results were calculated from three independent experiments and the data show the recovery of the wound. Data represent means $\pm \mathrm{SD}$. ${ }^{*} \mathrm{p}<0.05$.
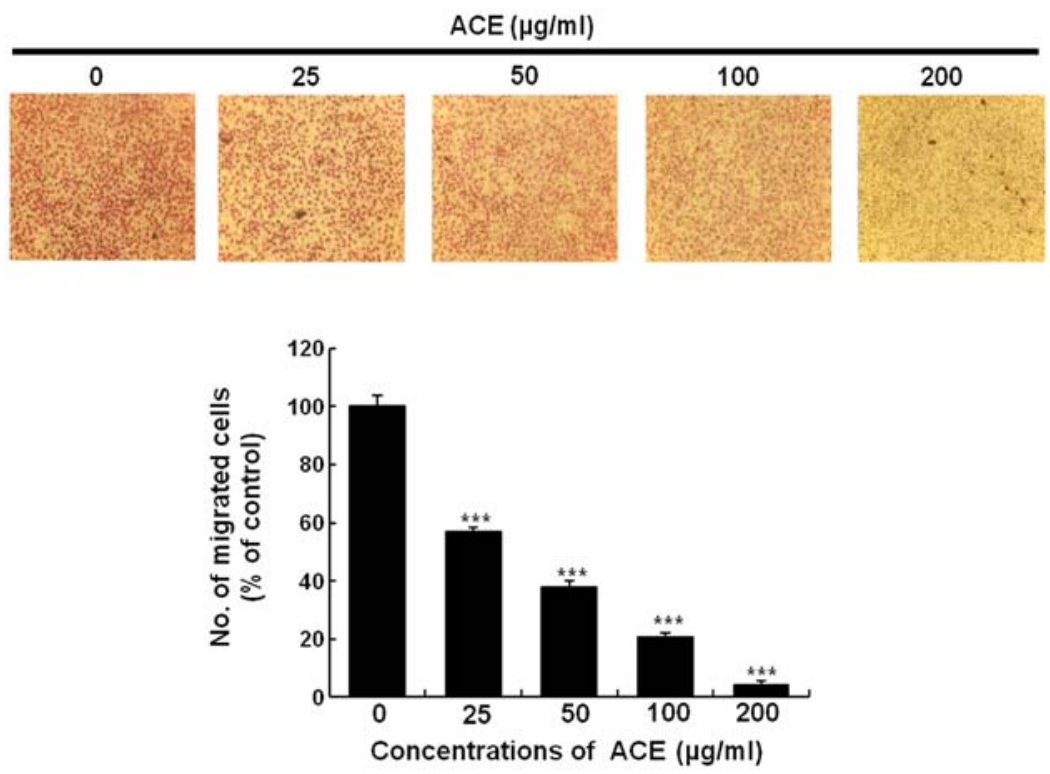

Figure 6. Inhibition of tumor cell migration by ACE. Inhibition of cell migration by ACE was examined by Transwell assay using Huh7 cells. Cells were treated with the indicated concentrations of ACE for $24 \mathrm{~h}$ and subjected to Transwell assay. Upper panel shows the representative images from triplicate samples. Data represent means \pm SD. ${ }^{* * * *} \mathrm{p}<0.001$.

decreased cell proliferation and migration of HCC cells. Since its discovery, various tumor-promoting effects of STAT3, including cell cycle progression, anti-apoptosis, angiogenesis, and invasion/migration, have been studied and considered as 
key factors in oncogenesis and cancer progression (27). In particular, long-term IL-6-mediated inflammatory responses and subsequent STAT3 activation have been implicated in various liver pathogenic conditions including hepatitis, liver fibrosis, cirrhosis, and HCC carcinogenesis (28), suggesting that inhibition of STAT3 activation can be an effective strategy to treat various liver diseases. Given that IL-6/STAT3 signaling plays a crucial role in HCC development and progression, it is conceivable that the anticancer effect of ACE on HCC might be attributable to its inhibitory activity on the IL-6/STAT3 signaling pathway and subsequent cell cycle-related gene expression.

Chronic infection of HBV is a leading cause of HCC development and approximately $15-40 \%$ of chronic hepatitis B patients may develop progressed liver diseases including cirrhosis and HCC. In our previous study, we showed that a male-specific mutation of HBV is closely related to HCC development through the activation of STAT3. Ectopic expression of W4P LHB strongly induces STAT3 activation in NIH3T3 cells and transforming of the cells (4). In the current study, ACE suppressed not only STAT3 activation in IL-6treated HCC cells but also STAT3 activation by W4P HBV LHB expression in fibroblast cells, suggesting that ACE may suppress tumorigenesis induced by HBV-mediated STAT3 activation. Thus, this study provides theoretical basis for the use of ACE in the treatment of HCC and prevention of HCC in chronic hepatitis patients.

The exact mechanisms of STAT3 inhibition by ACE and active ingredients inhibiting STAT3 activity remain elusive. Several compounds in ACE including capillarisin, scoparone, scopoletin and cholorogenic acid have been reported to suppress the activity of STAT3 (24,29-31). Thus, it can be postulated that several compounds in ACE are responsible for STAT3 inhibition. ACE treatment on HepG2 cells resulted in decrease of STAT3 protein levels, indicating that the suppression of STAT3 activity is partly due to the lowered level of STAT3 (Fig. 3A). However, STAT3 phosphorylation of NIH3T3 cells induced by W4P LHB expression was markedly reduced despite the similar protein level of STAT3, indicating that ACE is also capable of suppressing the activation of STAT3 (Fig. 4A and B).

Regulation of IL-6/STAT3 signaling by ACE suggests its potential as a therapeutic agent against various liver diseases related to IL-6/STAT3 inflammatory responses. Identification of the constituents responsible for the STAT3 inhibition and unveiling of underlying molecular mechanism remain to be elucidated.

\section{Acknowledgements}

This study was supported by a grant of the Korea Health Technology R\&D Project through the Korea Health Industry Development Institute(KHIDI), funded by the Ministry of Health and Welfare, Republic of Korea (grant number: HI14C0955).

\section{References}

1. Abiru S, Migita K, Maeda Y, Daikoku M, Ito M, Ohata K, Nagaoka S, Matsumoto T, Takii Y, Kusumoto K, et al: Serum cytokine and soluble cytokine receptor levels in patients with non-alcoholic steatohepatitis. Liver Int 26: 39-45, 2006.
2. Liu Y, Li P-K, Li C and Lin J: Inhibition of STAT3 signaling blocks the anti-apoptotic activity of IL-6 in human liver cancer cells. J Biol Chem 285: 27429-27439, 2010.

3. Svinka J, Mikulits W and Eferl R: STAT3 in hepatocellular carcinoma: New perspectives. Hepat Oncol 1: 107-120, 2014.

4. Lee SA, Kim H, Won YS, Seok SH, Na Y, Shin HB, Inn KS and Kim BJ: Male-specific hepatitis B virus large surface protein variant W4P potentiates tumorigenicity and induces gender disparity. Mol Cancer 14: 23, 2015.

5. Cronquist A: Vascular Flora of the Southeastern United States: Asteraceae. UNC Press Books, 2001.

6. Nibret E and Wink M: Volatile components of four Ethiopian Artemisia species extracts and their in vitro antitrypanosomal and cytotoxic activities. Phytomedicine 17: 369-374, 2010.

7. Han JM, Kim HG, Choi MK, Lee JS, Lee JS, Wang JH, Park HJ, Son SW, Hwang SY and Son CG: Artemisia capillaris extract protects against bile duct ligation-induced liver fibrosis in rats. Exp Toxicol Pathol 65: 837-844, 2013.

8. Cha J-D, Jeong M-R, Jeong S-I, Moon SE, Kim JY, Kil BS and Song YH: Chemical composition and antimicrobial activity of the essential oils of Artemisia scoparia and A. capillaris. Planta Med 71: 186-190, 2005.

9. Hong J-H, Hwang E-Y, Kim H-J, Jeong Y-J and Lee IS: Artemisia capillaris inhibits lipid accumulation in 3T3-L1 adipocytes and obesity in C57BL/6J mice fed a high fat diet. J Med Food 12: 736-745, 2009.

10. Lee J, Chae K, Ha J, Park BY, Lee HS, Jeong S, Kim MY and Yoon M: Regulation of obesity and lipid disorders by herbal extracts from Morus alba, Melissa officinalis, and Artemisia capillaris in high-fat diet-induced obese mice. J Ethnopharmacol 115: 263-270, 2008.

11. Mori H, Xu Q, Sakamoto O, Uesugi Y, Koda A and Nishioka I: Mechanisms of antitumor activity of aqueous extracts from Chinese herbs: Their immunopharmacological properties. Jpn J Pharmacol 49: 423-431, 1989.

12. Hong JH and Lee IS: Effects of Artemisia capillaris ethyl acetate fraction on oxidative stress and antioxidant enzyme in high-fat diet induced obese mice. Chem Biol Interact 179: 88-93, 2009.

13. Lee HI, Seo KO, Yun KW, Kim MJ and Lee MK: Comparative study of the hepatoprotective efficacy of Artemisia iwayomogi and Artemisia capillaris on ethanol-administered mice. J Food Sci 76: T207-T211, 2011.

14. Zhao Y, Geng CA, Ma YB, Huang XY, Chen H, Cao TW, He K, Wang H, Zhang XM and Chen JJ: UFLC/MS-IT-TOF guided isolation of anti-HBV active chlorogenic acid analogues from Artemisia capillaris as a traditional Chinese herb for the treatment of hepatitis. J Ethnopharmacol 156: 147-154, 2014.

15. Zhao Y, Geng CA, Chen H, Ma YB, Huang XY, Cao TW, He K, Wang $\mathrm{H}$, Zhang XM and Chen JJ: Isolation, synthesis and antihepatitis B virus evaluation of p-hydroxyacetophenone derivatives from Artemisia capillaris. Bioorg Med Chem Lett 25: 1509-1514, 2015.

16. Zhao Y, Geng CA, Sun CL, Ma YB, Huang XY, Cao TW, He K, Wang H, Zhang XM and Chen JJ: Polyacetylenes and antihepatitis B virus active constituents from Artemisia capillaris. Fitoterapia 95: 187-193, 2014

17. Kim KS, Yang HJ, Lee JY, Na YC, Kwon SY, Kim YC, Lee JH and Jang HJ: Effects of $\beta$-sitosterol derived from Artemisia capillaris on the activated human hepatic stellate cells and dimethylnitrosamine-induced mouse liver fibrosis. BMC Complement Altern Med 14: 363, 2014.

18. Wang J-H, Choi M-K, Shin J-W, Hwang S-Y and Son C-G: Antifibrotic effects of Artemisia capillaris and Artemisia iwayomogi in a carbon tetrachloride-induced chronic hepatic fibrosis animal model. J Ethnopharmacol 140: 179-185, 2012.

19. Altekruse SF, McGlynn KA and Reichman ME: Hepatocellular carcinoma incidence, mortality, and survival trends in the United States from 1975 to 2005. J Clin Oncol 27: 1485-1491, 2009.

20. Thomas MB and Zhu AX: Hepatocellular carcinoma: The need for progress. J Clin Oncol 23: 2892-2899, 2005.

21. Yang C-C, Lee M-R, Hsu S-L and Chang C-MJ: Supercritical fluids extraction of capillarisin from Artemisia capillaris and its inhibition of in vitro growth of hepatoma cells. J Supercrit Fluids 42: 96-103, 2007.

22. Hu YQ, Tan RX, Chu MY and Zhou J: Apoptosis in human hepatoma cell line SMMC-7721 induced by water-soluble macromolecular components of Artemisia capillaris Thunberg. Jpn J Cancer Res 91: 113-117, 2000. 
23. Hong SH, Seo SH, Lee JH and Choi BT: The aqueous extract from Artemisia capillaris Thunb. inhibits lipopolysaccharideinduced inflammatory response through preventing NF-kappaB activation in human hepatoma cell line and rat liver. Int $\mathbf{J}$ Mol Med 13: 717-720, 2004.

24. Lee JH, Chiang SY, Nam D, Chung WS, Lee J, Na YS, Sethi G and Ahn KS: Capillarisin inhibits constitutive and inducible STAT3 activation through induction of SHP-1 and SHP-2 tyrosine phosphatases. Cancer Lett 345: 140-148, 2014.

25. Yang SF, Chen MK, Hsieh YS, Yang JS, Zavras AI, Hsieh YH, Su SC, Kao TY, Chen PN, Chu SC: Antimetastatic effects of Terminalia catappa $\mathrm{L}$. on oral cancer via a down-regulation of metastasis-associated proteases. Food Chem Toxicol 48 : $1052-1058,2010$

26. Aggarwal BB, Kunnumakkara AB, Harikumar KB, Gupta SR, Tharakan ST, Koca C, Dey S and Sung B: Signal transducer and activator of transcription-3, inflammation, and cancer: How intimate is the relationship? Ann NY Acad Sci 1171: 59-76, 2009.

27. Furtek SL, Backos DS, Matheson CJ and Reigan P: Strategies and approaches of targeting STAT3 for cancer treatment. ACS Chem Biol 11: 308-318, 2016.
28. Subramaniam A, Shanmugam MK, Perumal E, Li F, Nachiyappan A, Dai X, Swamy SN, Ahn KS, Kumar AP, Tan BK, et al: Potential role of signal transducer and activator of transcription (STAT)3 signaling pathway in inflammation, survival, proliferation and invasion of hepatocellular carcinoma. Biochim Biophys Acta 1835: 46-60, 2013.

29. Kim JK, Kim JY, Kim HJ, Park KG, Harris RA, Cho WJ, Lee JT and Lee IK: Scoparone exerts anti-tumor activity against DU145 prostate cancer cells via inhibition of STAT3 activity. PLoS One 8: e80391, 2013.

30. Bhattacharyya SS, Paul S, Dutta S, Boujedaini N and KhudaBukhsh AR: Anti-oncogenic potentials of a plant coumarin (7-hydroxy-6-methoxy coumarin) against 7,12-dimethylbenz [a] anthracene-induced skin papilloma in mice: The possible role of several key signal proteins. Zhong Xi Yi Jie He Xue Bao 8: 645-654, 2010.

31. Tan Z, Luo M, Yang J, Cheng Y, Huang J, Lu C, Song D, Ye M, Dai M, Gonzalez FJ, et al: Chlorogenic acid inhibits cholestatic liver injury induced by $\alpha$-naphthylisothiocyanate: Involvement of STAT3 and NFKB signalling regulation. J Pharm Pharmacol 68: 1203-1213, 2016 